\title{
La escuela y la lengua en la construcción de la identidad nacional uruguaya: los libros de lectura usados en la escuela pública en los años 40 del siglo XX
}

\author{
Mariela Oroño* \\ Universidad de la República, Uruguay
}

\begin{abstract}
Resumen
Las políticas lingüísticas que apuntan a la promoción de determinadas lenguas o variedades de lenguas como vehiculares de la educación y de los valores nacionales, sustentan y generan representaciones que se transmiten mediante distintos tipos de discursos. Un tipo particular de políticas lingüísticas, representaciones y discursos sobre las lenguas es aquél que se origina en el marco de los procesos de construcción de la nacionalidad. Este trabajo analiza el lugar que se le adjudicó a la lengua en la consolidación del Estado nacional uruguayo y del ciudadano en los años 40 del siglo XX, así como el modo en que se articuló el lenguaje con otros referentes de la nacionalidad, en la serie de libros de lectura de Roberto Abadie y Humberto Zarrilli, textos oficiales del sistema escolar en este período de consolidación y expansión estatal. El análisis se contextualiza con otros documentos educativos de la época. El estudio muestra el modo
\end{abstract}

* Para correspondencia, dirigirse a: Mariela Oroño (marielaor@adinet.com.uy) Instituto de Lingüística, Facultad de Humanidades y Ciencias de la Educación, Universidad de la República. Magallanes 1577, Montevideo, Uruguay. 
en que la escuela, mediante la enseñanza de la lengua, se encargó de difundir representaciones nacionalistas, y tuvo un lugar destacado en la construcción de la identidad nacional.

Palabras clave: representaciones sociolingüísticas, escuela, libros de lectura, español, nacionalismo, Uruguay.

SCHOOL AND LANGUAGE IN THE CONSTRUCTION OF THE URUGUAYAN NATIONAL IDENTITY: THE READING BOOKS USED IN THE ELEMENTARY SCHOOL IN THE 40'S IN THE 20TH CENTURY

\begin{abstract}
Abadie and Zarrilli's books belong to the 40's in the 20th century. This period relates to the consolidation of citizenship. The purpose of this research is to study the sociolinguistic representations in Abadie-Zarrilli's reading books, as well as the documents about education related to them.

Collected data is considered according to the periods stated establishing the socio-historical and educational contexts. I study the relationship between language, nation and citizenship. School and language have played an important role in the construction of the national identity.
\end{abstract}

Keywords: sociolinguistic representations, elementary school, reading books, Spanish, nationalism, Uruguay.

Recibido: $31 / 03 / 14 \quad$ Aceptado: 20/05/14

\title{
1. INTRODUCCIÓN
}

Las políticas lingüísticas que apuntan a la promoción de determinadas lenguas o variedades de lenguas como vehiculares de la educación y de los valores nacionales sustentan y generan representaciones que se transmiten mediante distintos tipos de discursos. Un tipo particular de políticas lingüísticas, representaciones y discursos sobre las lenguas es aquél que se origina en el marco de los procesos de construcción de la nacionalidad. En el caso de Uruguay, este proceso implicó la elaboración de un modelo lingüístico y cultural forjado en torno a representaciones homogeneizadoras, 
que tuvieron al lenguaje como uno de sus protagonistas. En este proceso, el sistema educativo en general y los textos escolares para la enseñanza de la lengua en particular ocuparon un rol central.

En este trabajo analizo el lugar que se le adjudicó a la lengua en la consolidación del Estado nacional uruguayo y del ciudadano en los años 40 del siglo XX, así como el modo en que se articuló el lenguaje con otros referentes de la nacionalidad, en la serie de libros de lectura de Roberto Abadie y Humberto Zarrilli, textos oficiales del sistema escolar en este período de consolidación y expansión estatal. Contextualizo el estudio con otros documentos educativos de la época: La educación del pueblo (obra pedagógica del director del Consejo de Enseñanza Primaria y Normal, José Claudio Williman, 1937), el Programa escolar para las escuelas urbanas de 1941 y los Anales de Instrucción Primaria (publicación mensual del Consejo) ${ }^{1}$.

En el plano político, los libros se enmarcan en las dictaduras del doctor Gabriel Terra y del arquitecto y general Alfredo Baldomir (1933-1943); en el plano educativo, en la consolidación del sistema escolar, con la reforma liderada por el arquitecto José Claudio Williman (a partir de la intervención del sistema escolar por decreto de 1933). En este período, el contexto internacional determinó fuertemente la situación nacional. La dictadura de Terra se caracterizó por un endurecimiento de las políticas inmigratorias, como consecuencia de la crisis económica mundial de 1929, que también reorientó las políticas sociales estatales para frenar el intervencionismo popular del batllismo (Filgueira et al. 2003) y acrecentó el conflicto social: en este período se aprobaron la ley $\mathrm{n}^{\mathrm{o}} 8868$ (conocida como la "ley de indeseables") de 1932, la Constitución de 1934 y la ley n 9604 de 1936 para dificultar el ingreso de inmigrantes al país ${ }^{2}$. Estas medidas parecen haber tenido el efecto deseado. Según se indica en los Anales (Anales de Instrucción Primaria, Época II, Tomo VI, 1945: 267-268), la población inmigrante fue aumentando desde 1900 hasta 1930 (por ejemplo, en 1908 ingresaron al país 20.769 inmigrantes; en 1912, 25.928 y en 1929, 27.285).

\footnotetext{
1 El estudio forma parte de mi tesis de maestría sobre "Las representaciones sociolingüísticas en textos escolares de la educación primaria uruguaya: las series de libros de lectura de Vásquez Acevedo, Figueira y Abadie-Zarrilli” (FHCE- UDELAR).

2 La "ley de indeseables" establecía causales de "inadmisión" y de expulsión de extranjeros, aunque poseyeran "carta de ciudadanía nacional". La Constitución de 1934 dispuso algunas restricciones con respecto a la entrada de inmigrantes que padecían enfermedades físicas o mentales y no tenían una adecuada conducta moral. La ley $n^{\circ} 9604$, además de ratificar las trabas puestas por la "ley de indeseables", añadió otras nuevas como los "factores políticos" o la necesidad de poseer un certificado consular.
} 
Pero a partir de ese año, las cifras descendieron abruptamente (en 1931 ingresaron al país 4.646 inmigrantes; en 1933, 1.687 y en 1935, solamente $414)^{3}$. En este período predominó entonces una ideología conservadora con connotaciones xenofóbicas, dirigida por Terra y fuertemente influenciada por las ideas nazi-fascistas de la Europa de entreguerras (Ruiz 2008b).

En términos político-educativos, el período coincide con una reorientación pedagógica contraria a la Escuela $\mathrm{Nueva}^{4}$ mediante la reforma educativa liderada por el arquitecto José Claudio Williman. En los años 30 y 40 del siglo XX, el valor cultural y simbólico de la escuela primaria formaba ya parte de la identidad nacional $1^{5}$; para quienes estaban en el poder era un instrumento para controlar y encauzar las formas de convivencia colectiva y moldear el imaginario nacionalista. En ese sentido se impulsó una "reorientación patriótica" (Williman 1937) para defender un nacionalismo extremo. La reorientación patriótica buscada por Williman se enmarcaba en una revolución cultural que suponía la reforma de la escuela pública. El proyecto de reforma educativa de Williman está expuesto en La educación del pueblo, el extenso prólogo a la memoria del organismo correspondiente al año 1937. Williman proponía eliminar la orientación pedagógica de la Escuela Nueva e implantar "la educación para el esfuerzo", acompañada por la enseñanza del sentimiento patriótico, base de la "unidad nacional"; este aspecto era fundamental para "un país amenazado continuamente en su pureza nacional por una inmigración heterogénea y en su integridad nacional por su reducido poder físico" (CNEPN 1935: 11, 29-30). Para lograr su objetivo también estimaba necesario reorganizar la formación docente para "rectificar" la "formación espiritual de los futuros maestros" (op. cit.: 30).

3 Aunque no contamos con censos nacionales entre 1908 y 1963, en los Anales de Instrucción Primaria de 1945 (época II, Tomo VIII, n 3 y 4) se consigna una población total de 2.100.000 habitantes, una cuarta parte de los cuales eran inmigrantes.

4 La Escuela Nueva surgió en Europa y en los EE.UU. Tomó como referencia el pragmatismo pedagógico de John Dewey, quien desarrolló el principio de la "educación para la acción", frente a la clásica "educación para la instrucción" (Bralich 1987). En Uruguay fue tema de congresos de inspectores y de concursos, y a partir de una resolución del 15 de junio de 1928 sus autores fundamentales (John Dewey, Olive Decroly y María Montessori) integraban los programas de didáctica y pedagogía en la formación de maestros (Legislación escolar, Tomo X). Esta orientación pedagógica empezó a tener mayor relevancia en la educación pública desde inicios de 1930 cuando el doctor Santín Carlos Rossi asumió la dirección del CNEPN (Memoria del CNEPN 1933).

5 Para un estudio del lugar de la escuela y la lengua en la construcción de la identidad nacional uruguaya durante el último cuarto del siglo XIX, cfr. Oroño (2012) y (2013). 


\section{LA SERIE GRADUADA DE LIBROS DE LECTURA DE ROBERTO ABADIE Y HUMBERTO ZARRILLI}

Los textos escolares usados para la enseñanza de la lengua forman parte de los discursos institucionales producidos en el marco de políticas lingüísticas instrumentadas a través del sistema educativo. La declaración de un libro como de uso oficial en las escuelas o la realización de un concurso para tal fin suponen un fuerte control sobre los contenidos y la forma de los textos (incluyendo la variedad lingüística a usar). Las representaciones sociolingüísticas que transmiten los textos escolares influyen en el comportamiento y las creencias de sus destinatarios.

Las representaciones sociolingüísticas (Boyer 1991, 2003; Arnoux y Del Valle, 2010) son un tipo de representación social que involucra ideas socialmente compartidas acerca de una lengua. Se trata de "diseños más o menos complejos del universo social que los discursos sobre el lenguaje construyen, aunque hablan sólo del lenguaje" (Arnoux y Bein 1999: 9). Como señalan Arnoux y Del Valle (2010: 3), "por un lado, se refieren a objetos lingüísticos (lenguas, variedades, hablas, acentos, registros, géneros, modos de leer o de escribir, etc.) y [...], por otro, implican evaluaciones sociales de esos objetos y de los sujetos con los que son asociados". Las representaciones sociolingüísticas evalúan y categorizan socialmente a un individuo o grupo social, en función de sus comportamientos lingüísticos. Al vincular el orden lingüístico con el orden social, mostrando cómo se articulan, permiten comprender e interpretar otros aspectos de la realidad social.

En el proceso de conformación de los Estados nacionales, los textos escolares constituyeron un dispositivo normativo altamente institucionalizado y eficaz en la consolidación lingüística de la comunidad. A través de ellos en forma simultánea se indican las maneras de decir socialmente admitidas y se excluyen otras, y se define lo correcto y aceptable en comportamientos y prácticas que exceden el ámbito del lenguaje (Arnoux 2008; Arnoux y Del Valle 2010).

El poder de los textos escolares radica justamente en la escritura. La ciudad escrituraria (Rama 1998) permite, gracias a su cultura impresa, la existencia de la comunidad imaginada (Anderson 1993) nacional que pretende desconocer la diversidad de los grupos que la constituyen. El poder de la escritura se observa en su capacidad de crear el objeto, a la vez que habla de él; para el caso que interesa a este trabajo, la capacidad de crear el Estado nacional, el ciudadano y la lengua nacional a la vez que habla de ellos.

Los libros de lectura de Abadie-Zarrilli -tal como leemos en sus respectivas portadas- comienzan a utilizarse en las escuelas con carácter 
de textos oficiales en 1941, como resultado de haber ganado un concurso organizado por el Consejo Nacional de Enseñanza Primaria y Normal a tales efectos.

Humberto Zarrilli (Montevideo, 1898-1964) fue maestro, escritor y se desempeñó como docente en los Institutos Normales. En 1920 fue designado redactor-traductor de las revistas oficiales del Consejo Nacional de Instrucción Primaria, de cuya dirección se hizo cargo desde 1921 por más de veinte años. Roberto Abadie Soriano (Montevideo 1896-1992) fue maestro y se desempeñó como docente en todos los niveles del sistema educativo estatal. Abadie produjo cambios profundos en la doctrina y práctica de la educación uruguaya, especialmente en lo referido a la alfabetización, la educación de adultos, rural y para ciegos. Abadie y Zarrilli tenían en los años 40 del siglo XX una reconocida trayectoria en la elaboración de libros de lectura y de lenguaje para las escuelas públicas uruguayas.

Para cada año escolar (de primero a cuarto) hay un libro de lectura para el alumno y otro para el maestro: Libro primero de lectura, Libro segundo de lectura, Libro tercero de lectura y Libro cuarto de lectura. El libro para el alumno contiene únicamente textos. El libro para el maestro, además de los textos, contiene indicaciones didácticas en las que se especifica cuál es el interés de la lectura, "vicios de dicción", "comentario moral", reglas u observaciones ortográficas, "ejercicios de pronunciación”, "uso del diccionario", "explicación de modismos", y/o "ejercicios de redacción", para cada lectura. Cada libro - ya sea en su versión para el alumno o para el maestro - comienza con un extenso prólogo de sus autores en el que explican el Plan del libro. Las lecturas que componen los libros fueron escritas en su mayoría por sus autores para cumplir los propósitos pedagógicos de cada lección; se trata en gran parte de textos en prosa.

Los libros de lectura analizados se corresponden con la formulación de un nuevo programa para las escuelas urbanas: el programa escolar de 1941, que contemplaba los siguientes contenidos: Aritmética y Geometría; Idioma Nacional; El hombre y la naturaleza: Anatomía, Fisiología e Higiene; Moral; Historia; Cultura cívica; Geografía; Física, Química y Mineralogía; Dibujo; Trabajos manuales; Canto; Cultura fisica" (Consejo de Instrucción Primaria 1957). El programa también recogía la preocupación patriótica de Williman, especialmente en algunas materias:

Ha preocupado preferentemente a esta Comisión el programa de Idioma Nacional, [aunque] los programas de Moral, Historia y Educación Cívica, han merecido de parte de la Comisión una atención de preferencia, por razones que no escaparán al criterio del Honorable Consejo. Los ideales de nacionalidad, patriotismo, honestidad y civismo deben determinar el 
centro de toda educación que tienda a la formación de la personalidad (Consejo de Instrucción Primaria 1957: 5 y 7).

En los libros de lectura de Abadie-Zarrilli, las referencias al lenguaje son múltiples y comprenden aspectos tan diversos como el lugar de la lengua en la construcción de la nacionalidad, recomendaciones lingüísticas vinculadas con el comportamiento social, la relación entre lenguaje, pensamiento y conocimiento, y el valor de la lectura y la escritura.

\section{LA LENGUA EN LA CONSOLIDACIÓN DEL ESTADO NACIONAL URUGUAYO}

Como referente de la nacionalidad, la lengua aparece mencionada junto con otros aspectos como el arraigo al territorio, el orgullo por la historia de los antepasados y la defensa de las tradiciones ${ }^{6}$. El idioma nacional (fuera de toda discusión, el castellano) acompaña la defensa de la nacionalidad en el marco de la "educación patriótica". En este contexto de exaltación patriótica los inmigrantes y sus lenguas comenzaron a ser juzgados como elemento disolvente de la nacionalidad.

En el Plan de cultura patriótica para la formación de maestros, aprobado en 1938, se indicaba como una "orientación docente" la "orientalidad": "por sobre los rencores y rivalidades de los partidos políticos, de las ideologías enemigas y de las diversidades religiosas está la unión de todos los uruguayos en el amor a la Patria, en la resolución de defenderla y en las realizaciones efectivas para engrandecerla" (Anales de Instrucción Primaria, época II, Tomo I, 1938: 74). En consecuencia, se entendía que los uruguayos (y en especial los maestros, a quienes estaba dirigido este texto) "debemos estar siempre alertas sobre nuestras costas y fronteras" y tener en cuenta "El frente interno: profilaxis social ejercida por la Policía. Exaltación de la lucha contra los indeseables, los corruptores, los disolventes y los que atacan las estructuras esenciales de la nación" (op. cit.: 74).

En el Plan de cultura patriótica se representó al maestro como elemento fundamental de la educación:

6 A propósito, nótese que estos rasgos son también privilegiados en la construcción de identidades étnicas. 
Cualquiera sea el plan, cualesquiera sean los programas y los métodos, y contando además con instalaciones perfectas, la escuela fracasará siempre, fatalmente, si no se cuenta con el factor maestro. En cambio, un buen maestro hará siempre obra, aun teniendo en contra los otros factores (Williman 1937: 76).

Por ello, el interés en desarrollar un plan que le permitiera cumplir su función siguiendo la nueva orientación escolar.

La prensa oficialista de la época evaluó en términos positivos la aplicación de este plan de cultura patriótica y mostró especial preocupación por la presencia de inmigrantes en el país. En un artículo publicado en El Debate el 15 de mayo de 1938, titulado "Acción profundamente patriótica", se señalaba "la enorme trascendencia patriótica de la medida" (en Anales de Instrucción Primaria, época II, Tomo I: 1938: 58). Otro artículo publicado en El Pueblo el 10 de mayo de 1938, titulado "Fortalezcamos en el espíritu del niño el amor a la Patria”, expresaba:

Si siempre fue indispensable fortalecer el sentimiento patriótico en el espíritu de sus educadores y de los educandos, más evidentemente necesario es hacerlo ahora, en que corrientes exóticas, aluviones inmigratorios y desdichadas imitaciones de ideologías extranjeras procuran debilitar la personalidad nacional, negando el culto patriótico [...]. La escuela uruguaya debe contrarrestar la infiltración exótica y la perniciosa indiferencia respecto al sentimiento y el concepto de nacionalidad, y el maestro uruguayo, a su vez, debe iniciar su jornada, como el militar, con una íntima invocación a la patria y una última promesa de lealtad a la bandera que representa al país y flamea sobre su aula (En Anales de Instrucción Primaria, época II, Tomo I: 1938: 54).

En este período se exacerbó la función simbólica de la bandera y el himno nacionales como referentes de la nacionalidad. En este sentido hubo varias disposiciones del Consejo de Primaria que establecieron en forma detallada cuándo y cómo debía izarse el pabellón patrio, y el modo de cantar el himno nacional.

La lengua acompañó este tipo de acciones. Una resolución del Consejo de Primaria fechada el 3 de mayo de 1939 estableció que en los actos realizados para conmemorar fechas patrias, "no podrán cantarse himnos de países extranjeros ni figurará la bandera de ningún país extranjero, ni se usará otro idioma que el idioma nacional" (Legislación escolar, Tomo XII, 1942: 358). La lengua nacional es un factor recurrente en la conformación de la nacionalidad y, así como los inmigrantes no formaban parte de la nación, tampoco lo hacían sus lenguas. De todos modos, el hecho de que 
fuera necesario reglamentar el uso del idioma nacional en un acto escolar, caracterizado por la formalidad y el protocolo, muestra que efectivamente se hablaban en Uruguay también otras lenguas diferentes al español.

La relación entre nación, democracia, escuela y lenguaje, establecida en los documentos pedagógicos generales que orientaron la educación primaria en este período, condiciona las características de los libros de lectura de la época.

\subsection{El Plan de los libros de lectura de Abadie y Zarrilli}

En el Plan, Abadie y Zarrilli explican el procedimiento seguido para la elaboración de sus libros de lectura y su doble función: didáctica -como "instrumento educativo" para la enseñanza de la lengua (Abadie y Zarrilli, Libro cuarto, Plan, 1946: V)- e ideológica -como "propaganda patriótica" o "a favor de los ideales nacionalistas" (op. cit.: IX):

Sabido es que en la mayoría de los hogares toda la biblioteca está construida por los libros que los niños llevan de la Escuela. Estos libros son ojeados por los padres y, muchas veces, leídos por ellos. Este hecho obliga a los autores del libro de lectura y al Estado que lo aprueba, a darle, además de su condición didáctica, la de instrumento de propaganda a favor de los ideales nacionalistas (Abadie y Zarrilli, Libro cuarto, Plan, 1946: IV).

Abadie y Zarrilli reconocen que las medidas que se instrumentan desde el sistema educativo tienen un alcance muy grande. No solo porque -como ya hemos observado- a través de decretos, circulares y reglamentaciones puede recomendarse y hasta a obligarse a los docentes a cumplir con determinadas directivas, sino porque a través del sistema educativo puede llegarse a un número muy importante de la población; como señalan estos autores, los libros de lectura no son leídos únicamente por los escolares sino también por sus padres.

Los "ideales del libro" de lectura son "la moral" y "la patria", vinculada con la "conservación de su Idioma":

LA MORAL INDIVIDUAL, FAMILIAR Y SOCIAL, a través de la nobleza del hombre y de sus esfuerzos por superarse indefinidamente, de los afectos familiares y del trabajo, la perseverancia, el estudio y la solidaridad humana; y LA PATRIA, [...], a través de la conservación de su Idioma, el conocimiento de su Geografía y de su Historia (op. cit.: VII). 
Para alcanzar esos ideales es importante que los libros de lectura generen en los escolares el arraigo al territorio y el orgullo por la historia de los antepasados (componentes básicos de toda nación).

Abadie y Zarrilli otorgan a la literatura nacional un lugar importante en la difusión de estas ideas nacionalistas: "nos decidimos a hacer un libro que contuviera, además de las páginas que debíamos redactar nosotros mismos, una verdadera antología de prosistas y poetas preferentemente uruguayos" (Abadie y Zarrilli, Libro cuarto, Plan, 1946: VI). A través de la literatura se espera que el alumno conozca "la belleza de nuestra tierra, la emoción de nuestra historia, el encanto de nuestro folklore y la grandeza del alma nacional" (op. cit.: VI). También se equipara el rol de los poetas y escritores con la de los héroes nacionales, como referentes de la nacionalidad: "Tan verdad es esto, que todos lo aceptamos subconscientemente al equiparar la gloria de los escritores y poetas, con la de los héroes, fundadores de nuestra nacionalidad" (op. cit.: IX). Como se señaló más arriba, los escritores crean el relato nacional, al construir y difundir con sus obras los referentes de la nacionalidad. En este marco, el "idioma nacional" se concibe como un medio importante para "desarrollar el amor a la Patria". En la cita que sigue se señalan las funciones instrumental ("técnica indispensable para la vida") y simbólica del lenguaje (referente de la nacionalidad), esta última asociada además a la prescripción ("profanación o delito de lesa-patria su empleo indebido"):

La enseñanza del Idioma Nacional, además de su carácter de técnica indispensable para la vida, es medio eficaz para desarrollar el amor a la Patria. Día llegará en que el Idioma se considere tan sagrado como los símbolos, y que se estime, como profanación o delito de lesa-patria, su empleo indebido, tanto en su forma oral, como en su forma escrita (op. cit.: IX).

En una lengua de estandarización pluricéntrica como la española (Fontanella 1992), la denominación idioma nacional demarca las fronteras lingüísticas tanto en relación con España como con otros países hispanohablantes. Este parece ser el interés en el período estudiado: en el programa escolar de 1941 el capítulo dedicado a la enseñanza de la lengua se titula "Idioma Nacional" y, como se acaba de señalar, en los libros de lectura de Abadie y Zarrilli se entiende que uno de los medios para "desarrollar el amor a la Patria" (Libro cuarto, Plan, 1946: VII) es la enseñanza del "idioma nacional".

El siguiente texto, que Abadie y Zarrilli redactaron especialmente para su libro cuarto de lectura y que titulan "Patria", permite observar el estrecho vínculo que se establece entre el español como lengua común ("el mismo idioma") y la nación uruguaya: 
Aquí, donde tú vives, donde viven tus padres, donde vivirán tus hijos. Aquí, donde todos hablan el mismo idioma que te enseñó tu madre con las palabras más dulce que oirás en tu vida.

Aquí, donde la gloria que representa la bandera, imagen de nuestro brillante cielo, es tu propia gloria.

Aquí, donde aprenderás a ser libre y a respetar la libertad de los otros, es tu patria.

Pronuncia con amor su nombre: República Oriental del Uruguay.

Honrando a la patria, honras a tus mayores y te honras a ti mismo (Abadie y Zarrilli, Libro segundo, 1944: 71).

En este contexto, los inmigrantes y sus lenguas se visualizan como obstáculos para afianzar la nacionalidad y el idioma nacional. Para contrarrestar el problema, en la construcción imaginada de la comunidad (Anderson 1993), el gaucho se representa como figura mitológica capaz de "aglutinar" la población y lograr la unidad nacional, amenazada por "el confuso y amorfo oleaje que continuamente amenaza barrer lo que nos es propio" (Abadie y Zarrilli, Indicaciones didácticas, Libro cuarto, 1946: 52):

[...] el único elemento aglutinante que puede presentar nuestra joven nacionalidad, es la figura legendaria del gaucho y, a través de éste, la del charrúa ${ }^{7}$. [...] No olvidemos: la unidad nacional griega estaba basada en sus mitos comunes. Nosotros tenemos un mito, mezcla de realidad y de leyenda: el gaucho (op. cit.: XIII).

El gaucho es el "hombre que defiende y construye la Patria" (Abadie y Zarrilli, Libro segundo, Indicaciones didácticas, 1944: 47); "nuestro tipo nacional" (Abadie y Zarrilli, Libro cuarto, 1946: 71).

De este modo, la figura del gaucho se opone a la de los inmigrantes reales: "No siendo la población vegetativa la única de nuestro país y teniendo aún esta misma la característica de proceder de razas extranjeras, estamos expuestos a perder el carácter nacional" (Abadie y Zarrilli, Libro cuarto, Plan, 1946: XIII).

7 La ausencia de una explicación sobre la desaparición de los indígenas muestra el proceso de naturalización u opacamiento de una situación de violencia étnica como fue su exterminio, congruentemente con lo que señala Renan (1987 [1882]: 7-8) en relación con el olvido y el error histórico como factores esenciales en la construcción de una nación. En una lectura se dice, por ejemplo: "Hace mucho tiempo el Uruguay estaba habitado por indios. [...] Estos indios eran salvajes. [...] Ya no existen indios" (Abadie y Zarrilli, Libro segundo, texto, 1944: 103). 
En el Plan analizado se establece una oposición entre los que pertenecían a "razas extrañas" o "extranjeras" (Abadie y Zarrilli, Libro cuarto, 1946: IV) y los que formaban parte de "nuestro pueblo". Asimismo, se advierte sobre la amenaza que podían representar los escolares hijos de inmigrantes por los valores que sus padres podían transmitirles en relación con su patria de origen, que entre otros aspectos incluiría el menosprecio por el idioma nacional ("nuestro idioma"):

Un elevado porcentaje de nuestros escolares proceden de razas extrañas y muchos de ellos no son ni siquiera nacidos en el país. Esta circunstancia hace que los padres inculquen a sus hijos, como es natural, el amor a los héroes de su país de origen, y que lleguen a más, como lo hemos comprobado, es decir, que menosprecien a los nuestros a causa del reducido escenario en que actuaron. $Y$ no sólo pasa esto con respecto a nuestros héroes militares y cívicos, sino también, con lo que se refiere a nuestra literatura, a nuestras artes, a nuestras industrias y aún a nuestro idioma y a las costumbres de nuestro pueblo (op. cit.: IV).

En el Plan, los atributos autóctonos se evalúan como positivos e incluso excepcionales, en oposición a los extranjeros:

\begin{tabular}{|c|c|}
\hline Evalu & Evaluación de lo extranjero \\
\hline $\begin{array}{l}\text { "la belleza de nuestra tierra" (Abadie y } \\
\text { Zarrilli, Libro cuarto, Plan, 1946: VII) } \\
\text { "la emoción de nuestra historia" (op. } \\
\text { cit.: VII) } \\
\text { "el encanto de nuestro folklore" (op. cit.: } \\
\text { VII) } \\
\text { "la grandeza del alma nacional" (op. cit.: } \\
\text { VII) } \\
\text { "Día llegará en que el Idioma se considere } \\
\text { tan sagrado como los símbolos" (op. cit.: } \\
\text { IX). }\end{array}$ & $\begin{array}{l}\text { "razas extrañas" (op. cit.: IV) } \\
\text { "menosprecien a (...) nuestros [héroes], } \\
\text { (...) a nuestra literatura, a nuestras } \\
\text { artes, a nuestras industrias y aún a } \\
\text { nuestro idioma y a las costumbres de } \\
\text { nuestro pueblo" (op. cit.: IV) } \\
\text { "para que haya menos ingratos entre los } \\
\text { que cobijamos" (op. cit.: IX) } \\
\text { "el confuso y amorfo oleaje que } \\
\text { continuamente amenaza barrer lo que } \\
\text { nos es propio" (op. cit.: XIII). }\end{array}$ \\
\hline
\end{tabular}

Se construye un "nosotros" apuntalado en el uso reiterado del pronombre posesivo de primera persona plural ("nuestros héroes", "nuestra literatura", "nuestro idioma", "nuestras costumbres"); se opone un "nosotros" integrante y constructor de la nación uruguaya, a un "ellos" extranjero, invasor, amenazante y peligroso. "Ellos" son básicamente los inmigrantes. Esta construcción dicotómica de la patria se extiende al lenguaje: idioma nacional versus lenguas extranjeras. Como señala Di Tullio (2003: 107), "al 
imponerse el imperativo patriótico", el idioma nacional se convierte también en el "lazo con la tradición y expresión visible de la nacionalidad frente a los inmigrantes"; en la medida en que es la lengua de la enseñanza estatal, también el idioma nacional se constituye en el instrumento de nacionalización de los extranjeros (op. cit.).

\subsection{LA LENGUA EN LA FORMACIÓN DEL MODELO DE CIUDADANO}

Williman seguía la tradición vareliana ${ }^{8}$ al señalar que la escuela debía encargarse de formar al ciudadano: "Aceptamos como principio que la educación del pueblo debe preparar al individuo para ser ciudadano de una república" (Williman 1937: 33). No obstante ello, Williman tenía una concepción conservadora y elitista de la educación; consideraba que todos los ciudadanos debían ser educados en una "cultura mínima" pero solo algunos debían alcanzar niveles superiores:

[...] la enseñanza primaria y la secundaria deberían ser recibidas por todos los individuos, luego se produce una clasificación de éstos, dirigiéndose una parte a las actividades manuales u oficios, otra a la función de empleados comerciales o administrativos y otra mucho menor hacia las profesiones (op. cit.: 20).

La enseñanza debía estar al servicio de una estructura socio-económica, donde cada persona debía ocupar un lugar predeterminado. Los "peones", "braceros" y "obreros" (op. cit.: 20-21), poseedores solo de una cultura mínima, debían estar al servicio de los "ciudadanos de excepción": "la investigación científica [...] pudo ser posible cuando algunos hombres estuvieron en condiciones de dedicarse enteramente a observar y a reflexionar, gracias a que otros hombres se encargaron de resolverles a aquellos los otros problemas de la vida" (op. cit.: 16). Para Williman, los ciudadanos de excepción constituían una pequeña selección, imprescindible para que toda sociedad alcanzara la cultura superior. Y resumía: "las sociedades que, por una mala interpretación de la igualdad social, se han opuesto a la existencia de esa selección, han caído en la cultura inferior" (op. cit.: 21).

\footnotetext{
8 El sistema escolar estatal uruguayo se estructuró a partir de 1877 con la reforma liderada por el pedagogo José Pedro Varela. Sus principios centrales (obligatoriedad, gratuidad, laicidad) continúan vigentes.
} 
Los libros de lectura de Abadie y Zarrilli no reflejan tan claramente, sin embargo, la concepción elitista de la educación que expresaba Williman en La educación del pueblo (1937). Tal vez porque los autores no estaban de acuerdo con la propuesta de Williman, tal vez porque la educación primaria a la que se orientaban los libros estaban dentro de la cultura mínima que debían recibir todos los ciudadanos, tal vez por la dificultad de trasladar esa concepción a libros de lectura pensados para ser usados en un sistema escolar que no hacía excepciones ni categorizaciones de alumnos, salvo las del nivel educativo o año escolar, o porque aunque hubiera cambiado la orientación de las autoridades del Consejo de Educación Primaria y Normal, la tradición instalada no admitía cambios sustanciales de concepción. Sea como sea, las ideas fundamentales de Williman no se perciben, como señalamos, en los libros de lectura estudiados.

A continuación presento la relación que se establece en los libros de lectura entre el lenguaje y otros aspectos que se consideran valiosos para la construcción del ciudadano (lectura y escritura, patriotismo y moral, comportamientos sociales adecuados, conocimiento y claridad de pensamiento).

\subsubsection{La "educación patriótica" y la enseñanza moral}

En el marco de la educación patriótica del período y en consonancia con lo observado en los apartados anteriores, el programa escolar de 1941 indicaba que "los ideales de nacionalidad, patriotismo, honestidad y civismo deben determinar el centro de toda educación que tienda a la formación de la personalidad" (Consejo de Instrucción Primaria 1957: 7). Para ello, en el programa de Idioma Nacional se proponía trabajar muy especialmente con el tema "La Patria" (op. cit.: 22).

Los libros de lectura de Abadie-Zarrilli cumplen cabalmente con lo indicado en el programa, con una inclusión de textos seleccionados para tal fin. Para inculcar el sentimiento patriótico debía agregarse "a los comentarios poéticos y folklóricos [de las lecturas], la exaltación patriótica" (Abadie y Zarrilli 1943: 7) por medio de la emoción": "Creemos, y así lo demostramos, que la única manera de lograr la educación patriótica es por el camino de la emoción" (Abadie y Zarrilli 1944: 13) y consideran que la lectura es el medio de despertar la emoción, cuestión que ya había sido señalada por

\footnotetext{
9 El componente emocional de los discursos nacionalistas uruguayos también aparece en períodos posteriores, tanto con gobiernos dictatoriales (Barrios y Asencio 2003) como democráticos (Oroño y Pugliese 2008).
} 
Williman (1937: 58): "Será posible provocar la emoción, especialmente en la lectura, en la anécdota y el relato ejemplares, en los que intervengan el desinterés, el amor al prójimo, la franqueza y todos los sentimientos y los procedimientos morales que despiertan admiración".

En el programa escolar de 1941 también se indica el valor de las lecturas escolares para la enseñanza de la moral:

Del ambiente moral de la escuela, del ejemplo de la maestra, de las conversaciones ocasionales, de las lecturas, biografías y lecciones de historia y de las clases especiales de moral, se derivarán, no sólo las normas prácticas correspondientes a la conducta moral de estos niños, sino que se pondrá el fundamento de un criterio moral que afirmarán, con la experiencia y con la capacidad de juzgar y de emocionarse ante lo bello y lo noble de la vida (Programa de Moral, $5 .^{\circ}$ año: 42).

En relación con el valor de las lecturas para la enseñanza moral, Abadie y Zarrilli explican que una de "las conquistas alcanzadas por la escuela uruguaya fue la de sustituir el 'leer por leer' por el 'leer para aprender"' (Libro primero, Plan, 1943: 7), entendiendo este concepto solamente en su sentido moral: "Sin que ninguna lección tenga el aspecto de página instructiva o moralizadora, que tanto fastidia a los niños, todas ellas conducen, por sugestión o por emoción, a la adquisición de una verdad o a la simpatía por la realización del bien" (Abadie y Zarrilli, Libro primero, Plan, 1943: 9).

La excelencia moral se considera una cualidad de los héroes nacionales; de este modo se vincula la enseñanza moral con la educación patriótica:

Nada contribuye tanto a despertar el amor a la Patria, como la certeza de que éste es un país en que abundan los hombres de alta jerarquía moral e intelectual. Por eso, el mejor medio de educación patriótica es la Historia humanizada, no simplemente cronológica, donde cada episodio de la vida de los grandes patriotas sea un estimulante, un ejemplo que cada uno de nosotros quisiera imitar (Abadie y Zarrilli, Libro segundo, Indicaciones didácticas, 1944: 76).

\subsubsection{Urbanidad y buenos modales}

Aunque en los libros de lectura y en los programas escolares del período se vincula fundamentalmente la enseñanza de la lengua con la enseñanza moral y patriótica, en algunos casos también se la relaciona con la corrección social; así, por ejemplo, forma parte de los buenos modales comportarse correctamente en la mesa y no intervenir en las conversaciones de los adultos: 
Sé agradable en la mesa [...]. No intervengas en las conversaciones de los mayores. [...] elogia los platos que ha preparado tu madre con tanto trabajo y deseo de agradar. Tú puedes pagar a tus padres ese esfuerzo demostrándoles, en la mesa, que eres un niño delicado y bueno. A cambio de todo lo que te dan no te piden más que esto. ¿Y se lo vas a negar? (Abadie y Zarrilli, Libro segundo, texto, 1944: 39).

El mensaje es que un comportamiento semejante transforma al niño en buen hijo. Se pretende moldear a un niño sumiso frente a la autoridad, amable y fundamentalmente autocontrolado, sobre todo en la expresión de sus sentimientos y pensamientos: "Si quieres ser agradable sé como el sol. [...] guarda para ti las manchas y da tu luz, tan sólo, a los demás. Transforma tus arrebatos en sonrisas y dulces palabras. Sé generoso y sé amable como el sol" (Abadie y Zarrilli, Libro tercero, texto, 1944: 3).

Un referente importante de este comportamiento es el héroe nacional, José Artigas: "Todo su aspecto era varonil, sin dejar por ello de ser cortés y afable" (Abadie y Zarrilli, Libro tercero, texto, 1944: 82).

La obediencia a los mayores y el respeto a la autoridad son muy valorados. La obediencia, que implica autocensura y autocontrol (en todos los aspectos, incluyendo el lenguaje), es un atributo imprescindible de todo sujeto pasible de control y regulación, por lo que se la representa como el origen de otros valores sociales, como la salud, la bondad, la inteligencia y la felicidad. Por ejemplo:

El amor a los padres se demuestra obedeciéndolos

La única manera que tienen los niños de demostrar que quieren a sus padres, es obedeciéndolos.

La obediencia, además de ser una prueba de amor, es la salvaguarda de la salud y aún de la vida de sus hijos.

Los padres conocen los peligros a que están expuestos sus hijos. Obedeciendo sus consejos, el niño los evita y ahorra a sus padres, que lo quieren tanto, muchos dolores.

Se puede ser niño sano, inteligente, bueno, alegre, nada más que con obedecer a los padres.

Los niños no deben tan sólo cumplir aquellas órdenes cuya ejecución es un placer, sino también aquellas que exigen dominar un capricho o privarse de algo que les agrada.

Tampoco deben obedecer a regañadientes o mostrando mala cara, cuando la obediencia implica sacrificio" (Abadie y Zarrilli, Libro cuarto, 1946: 54). 
La prudencia, el recato y la honradez en todos los aspectos, incluyendo la lengua, son valores fundamentales: "La honradez y la prudencia en la acción y en la palabra" (Programa de Moral, $3 .^{\circ}$ año: 40).

El objetivo de la obediencia, la prudencia y la honradez era lograr un comportamiento puro, tanto en lo moral, como en lo lingüístico y social: "Pureza en los pensamientos, palabras y acciones" (Programa de Moral, 6. ${ }^{\circ}$ año, p. 45). Mediante este comportamiento se alcanzaría la salud (física, moral y social), imprescindible para alcanzar la felicidad. El resultado sería entonces la creación de "un niño perfecto":

\section{Las acciones}

¿Qué te parece que hago para estar tan sano?

Ya sé que dirás que madrugo, me baño, me desayuno sin glotonería, que hago ejercicios, que obedezco a mis padres, que juego sin molestar a nadie, que río y canto en lugares y en horas oportunas, que trabajo con gusto en la Escuela y en mi casa, que estudio, que almuerzo bien, que paseo al aire libre, que respiro por la nariz, que me limpio los dientes y me acuesto temprano.

Todas estas acciones y muchas más hago para estar sano.

Pero como esto sólo no basta para ser un niño completo, realizo otras acciones para ser bueno y para ser inteligente.

Si hablo con mis padres me dirijo siempre a ellos con cariño.

Si me piden algo, obedezco y también sonrío.

Si mi hermano o un compañero me resulta terco, no lo imito, antes bien, cedo.

Si una lección me resulta difícil, no renuncio a comprenderla, sino que me empeño más para aprenderla.

¡Qué placer siento entonces!

Estas y otras acciones son las que hacen a un niño perfecto (Abadie y Zarrilli, Libro tercero, 1944: 92-93).

De este modo, los niños eran adoctrinados para asumir un rol pasivo de ciudadanos, respetuosos de la jerarquía familiar y escolar.

\subsubsection{Lenguaje, conocimiento y pensamiento}

El programa de Idioma Nacional de este período (1941) relaciona la corrección en el lenguaje con la expresión del conocimiento, en el entendido de que hablar con corrección facilita la expresión correcta del pensamiento:

Durante todas las horas de clase acostúmbrese al niño a una expresión cuidada y correcta, aunque sin afectación, haciéndole comprender que, 
en la mayoría de los casos, es tan importante el poseer un conocimiento como la correcta expresión del mismo (Programa de Idioma Nacional, Lenguaje, $3 .^{\circ}$ año: 24$)$.

El vínculo que se establece entre lenguaje, conocimiento y pensamiento guarda relación con la propiedad de intelectualización de la lengua estándar (Garvin y Mathiot 1974) que, gracias a sus características léxicas y gramaticales, permite "formulaciones precisas y rigurosas y si es necesario abstractas, en otras palabras, una tendencia hacia la expresión cada vez más precisa y definida" (op. cit.: 305).

Se entiende que la escuela debe destacar la importancia de hablar bien; expresarse con corrección debe transformarse en una necesidad para el estudiante:

Al terminar la Escuela Primaria, los alumnos deben sentir la necesidad de expresarse bien en la conversación corriente, así como en la exposición de sus conocimientos y en las respuestas concretas y precisas a cualquier pregunta que se les formule (Programa de Idioma Nacional, Lenguaje, 6. ${ }^{\circ}$ año: $31-32$ ).

El modelo de corrección cultural de los estudiantes es el maestro, quien debía poseer "una cultura de cierta extensión y de cierta altura, un panorama completo del mundo comprendiendo los asuntos de más importancia y sus recíprocas relaciones" (Williman 1937: 78). Esta posición se refleja en las indicaciones didácticas de los libros de lectura estudiados, que colocan al maestro como modelo de corrección; es el encargado de evaluar el habla de los niños y corregirla, ofreciéndose él mismo como modelo, lo que le imponía a su vez la exigencia de apropiarse y de transmitir la norma lingüística ejemplar.

Los libros de lectura estudiados también se encargaron de difundir el modelo de ejemplaridad lingüística. En otro trabajo (Oroño 2011) he señalado que en sus libros de lectura Abadie y Zarrilli admiten algunos rasgos lingüísticos locales ${ }^{10}$ (el seseo en general y el yeísmo en todos los contextos salvo la lectura en voz alta), pero niegan el voseo como modelo de corrección, que se representa en términos puristas como un "vicio de dicción", junto

\footnotetext{
10 El proceso de estandarización pluricéntrica del español implicó la consolidación de algunos rasgos lingüísticos que se constituyeron en normas regionales. Dos de ellos conllevan una fuerte identificación rioplatense: el yeísmo rehilado y el voseo. El seseo, compartido con el resto de América y con el español del sur de España y de Canarias (Fontanella 1992), también caracteriza al español rioplatense.
} 
con otros fenómenos comunes "al habla corriente de nuestro pueblo". Por ejemplo: "Procúrese que los alumnos no cometan los siguientes vicios de dicción, que son tan comunes en el lenguaje corriente de nuestro pueblo: No debe decirse [...] Vos querés, Vos sos [...] Debe decirse Tú quieres, Tú eres" (Abadie y Zarrilli, Libro tercero, 1944: 37).

El purismo de estilo predominante privilegió en general los usos cultos y proscribió los fenómenos lingüísticos "populares". Retomando la dicotomía ya planteada por Bello (1859 [1847]), se aceptó lo local solo si formaba parte del habla culta. Los fenómenos citados como incorrectos refieren básicamente a variación sociolectal no necesariamente diatópica. La mayor parte de las observaciones prescriptivas corresponden a fenómenos fónicos, que comprenden aspectos vinculados con la pronunciación de diptongos y hiatos (güevo por "huevo", pior por "peor", etc.), grupos consonánticos (frustado, almiro, por "frustrado", "admiro", etc.), terminaciones de participios ("colorao" por "colorado", etc.) y uso de -s final de palabra ("lo clavele" por "los claveles", etc.), entre otros ${ }^{11}$. A nivel morfológico se destaca la referencia a fenómenos verbales vinculados con diptongaciones ("apreta" por "aprieta", etc.) y conjugaciones de verbos irregulares ("haiga" por "haya, etc.), además del voseo ("vos sos" por "tú eres", etc.). Cabe destacar que las representaciones nacionalistas y xenofóbicas analizadas en este artículo no se reflejaron en una prescripción de rasgos o lenguas migratorias, ya que no hay señalamientos puristas contra posibles extranjerismos (cfr. Oroño 2011).

\section{CONSIDERACIONES FINALES}

Este trabajo ha mostrado cómo las representaciones y políticas lingüísticas en el Uruguay de los años 40 del siglo XX respondieron al contexto histórico en que fueron difundidas. Las circunstancias políticas, económicas, sociales, educativas e ideológicas del contexto en que aparecieron y circularon los documentos analizados se reflejan en las representaciones sociolingüísticas que difunden.

11 En algunos casos, los fenómenos fónicos involucran también la morfología (las terminaciones de participios) y morfosintaxis (-s final de palabra en los casos de sintagmas nominales plurales). 
En los años 40 del siglo XX, la escuela y la enseñanza de la lengua tuvieron un rol central como modeladores del imaginario comunitario. La escuela fue vista como un instrumento idóneo para consolidar el Estado uruguayo a través de la difusión de representaciones nacionalistas, incluyendo el lenguaje. Mediante la enseñanza en español y del español se difundieron representaciones sobre un modelo de país y de ciudadano.

Uruguay fue representado como una nación homogénea, con un nacionalismo exacerbado y xenofóbico que reflejaba la posición del gobierno en relación con el contexto internacional. Mediante la "educación patriótica" y el uso de los libros de lectura como "propaganda patriótica" se buscaba defender la nacionalidad contra la amenaza extranjera. El gaucho ("nuestro tipo nacional"), junto con el territorio, la historia, las tradiciones y el español (referente lingüístico exclusivo de la nacionalidad; el "idioma nacional"), fueron los referentes locales, en oposición a los inmigrantes. En este sentido llama la atención que no se haga referencia alguna a la población luso-hablante (y al portugués), minoría lingüística histórica del país. La crisis económica y el cambio ideológico en el organismo directivo de la educación favorecieron asimismo la representación de la población inmigrante en términos negativos, visualizándola como problema, aun cuando era numéricamente inferior a la del siglo anterior.

La escuela fue concebida como un lugar central para moldear al ciudadano, de ahí el interés en reorientarla a las nuevas concepciones imperantes. La reforma escolar de Williman consideraba que la educación debía formar "ciudadanos de excepción". Sin embargo, los libros de lectura de Abadie y Zarrilli no reflejaron los aspectos centrales de esta concepción, sino que relacionaron la enseñanza de la lectura y de la escritura fundamentalmente con la "educación patriótica". Además de su función alfabetizadora, los libros de lectura se usaron como instrumentos para inculcar al niño los valores modernos. El contexto político imperante de restricción de libertades individuales exacerbó esta posición, que se encargó de difundir la obediencia y el autocontrol extremos como ejemplares. El modelo social se acompasó con el modelo lingüístico, reforzándose mutuamente. El niño debía internalizar una ideología nacionalista (el patriotismo), pero también purista (modelos de corrección). Los libros de lectura funcionaron como guardianes públicos del uso (Milroy y Milroy 1985), al transmitir determinados comportamientos sociales y lingüísticos como ejemplares, y evaluarlos negativamente en caso de ser transgredidos. 


\section{REFERENCIAS BIBLIOGRÁFICAS}

ANDERSON, BENEDICT. 1993. Comunidades imaginadas. Reflexiones sobre el origen y la difusión del nacionalismo. Buenos Aires: Fondo de Cultura Económica.

ARNOUX, ElviRA NARVAJA DE. 2008. Los discursos sobre la nación y el lenguaje en la formación del Estado (Chile, 1842-1862). Estudio glotopolitico. Buenos Aires: Santiago Arcos Editor.

Arnoux, Elvira Narvaja de y Roberto Bein. 1999. Introducción. Las representaciones del lenguaje. En Elvira Narvaja de Arnoux y Roberto Bein (comps.). Prácticas y representaciones del lenguaje, pp. 9-15. Buenos Aires: Eudeba.

Arnoux, Elvira Narvaja de y José del Valle. 2010. Las representaciones ideológicas del lenguaje. Discurso glotopolítico y panhispanismo. Spanish in Context 7(1): 1-24.

Barrios, Graciela y Pilar Asencio. 2003. La campaña de alfabetización de 1982 en la prensa de la época. Memoria para armar, III, vol. 1, pp. 153-160. Montevideo: Senda.

Bello, ANDRÉs. 1859. Gramática de la lengua castellana destinada al uso de los americanos. En: (s/d) Clásicos Tavera. Serie Lingüística y antecedentes literarios de la Península Ibérica. Antiguas gramáticas del castellano. Madrid, Digibus publicaciones digitales.

Boyer, Henri. 1991. Langues en conflit. París: L'Harmattan.

2003. De l'autre côté du discours. Recherches sur le fonctionnement des représentations communautaires. París: L'Harmattan.

Bralich, Jorge. 1987. Breve historia de la educación en Uruguay. Montevideo, Centro de Investigaciones y Estudios Pedagógicos.

Di Tullio, Ángela. 2003. Políticas lingüísticas e inmigración: el caso argentino. Buenos Aires: Eudeba.

Filgueira, Fernando, Adolfo Garcé, Carlos Ramos y Jaime Yaffé. 2003. Los ciclos del Estado uruguayo en el siglo XX. En Benjamín Nahum (dir.). El Uruguay del siglo XX. tomo II, pp. 173-205. Montevideo: Banda Oriental-Instituto de Ciencia Política.

Fontanella de Weinberg, Beatriz. 1992. El español en América. Madrid: Mapfre.

Garvin, Paul y Madeleine Mathiot. 1974. La urbanización del idioma guaraní. Problema de lengua y cultura. En Paul Garvin y Yolanda Lastra (comps.). Antología de estudios de etnolingüística y sociolingüística, pp. 303-313. México: UNAM.

Milroy, James y Lesley Milroy. 1985. Authority in language. Investigating language prescription and standardization. Londres: Routledge y Kegan Paul.

Oroño, Mariela y Leticia Pugliese. 2008. Planificación lingüística en el Uruguay: el programa de alfabetización "En el país de Varela: yo sí puedo". En Actas del XV Congreso Internacional de la Asociación de Lingüistica y Filología de América Latina (ALFAL). Montevideo: ALFAL. Publicado en CD, ISBN 956-310-179-0.

OroÑo, Mariela. 2011. La escuela pública uruguaya y el idioma nacional en dos períodos históricos: fines del siglo XIX y mediados del siglo XX. Letras 42: 217-247.

2012. La escuela y la lengua en la construcción discursiva de la identidad nacional: los libros de lectura usados en la escuela uruguaya en el último cuarto del siglo XIX. En Laura Masello (dir.). Lenguas en la región. Enseñanza e investigación para la integración desde la universidad, pp. 77-96. Montevideo: Mastergraf.

2013. Las representaciones sociolingüisticas en textos escolares de la educación primaria uruguaya: las series de libros de lectura de Vásquez Acevedo, Figueira y AbadieZarrilli. Tesis para obtener el título de Magíster en Ciencias Humanas, opción Lenguaje, Cultura y Sociedad, Universidad de la República.

Rama, Ángel. 1998. La ciudad letrada. Montevideo: Arca. 
Renan, ERnest. 1987. ¿Qué es una nación? En Ernest Renan, Cartas a Strauss, pp. 55-86. Madrid: Alianza Editorial.

Ruiz, Esther. 2008a. Del viraje conservador al realineamiento internacional. 1933- 1945. En

Ana Frega, Ana María Rodríguez, Ester Ruiz, Rodolfo Porrini, Ariadna Islas, Donatto

Bonfanti, Magdalena Broquetas e Isabel Cuadro. Historia del Uruguay en el siglo XX (1890-2005), pp. 85-122. Montevideo: Banda Oriental.

2008b. El Uruguay próspero y su crisis. 1946-1964. En Ana Frega, Ana María

Rodríguez, Ester Ruiz, Rodolfo Porrini, Ariadna Islas, Donatto Bonfanti, Magdalena

Broquetas e Isabel Cuadro. Historia del Uruguay en el siglo XX (1890-2005), pp. 123-

162. Montevideo: Banda Oriental.

\section{Documentos ANALIZADOS}

Abadie, Roberto y Humberto Zarrilli. 1943. Libro primero de lectura. Montevideo: Impresores Colombino.

1944. Libro segundo de lectura. Montevideo: Impresores Colombino.

1944. Libro tercero de lectura. Montevideo: Impresores Colombino.

1946. Libro cuarto de lectura. Montevideo: Impresores Colombino.

Consejo de Instrucción Primaria. 1957. Programas escolares. 1897-1957. Montevideo: Imprenta El Siglo Ilustrado.

Consejo Nacional de Enseñanza Primaria y Normal. 1935. Memoria. Años 1933-1934. Montevideo, Imprenta Nacional.

Dirección General de Instrucción Pública. 1938. Anales de Instrucción Primaria. Publicación mensual. Época II. Tomo I.

1945. Anales de Instrucción Primaria. Publicación mensual. Época II. Tomo VI. 1945. Anales de Instrucción Primaria. Publicación mensual. Época II. Tomo VIII.

Williman, José Claudio. 1937. La educación del pueblo. Montevideo: Imprenta Nacional. 